\title{
Blood pressure profile and impact of $M T H F R$ genotype in adults aged 60 to 102 years: preliminary findings
}

This abstract was awarded the student prize.

This abstract was awarded the FSAI prize for best oral presentation.

Hypertension affects an estimated 1 billion people and has been identified as the primary cause of preventable mortality worldwide ${ }^{(1)}$. The $677 \mathrm{C} \rightarrow \mathrm{T}$ polymorphism in the gene encoding the folate-metabolising enzyme methylene tetrahydrofolate reductase (MTHFR) increases the risk of hypertension by up to $87 \%$ and, correspondingly, stroke risk by up to $40 \%$. Randomised controlled trials (RCTs) from this centre have shown that supplemental riboflavin (co-factor for MTHFR) can lower blood pressure (BP) in hypertensive patients with the variant MTHFR 677TT genotype in middle age ${ }^{(2)}$. Irrespective of $M T H F R$ genotype, age is the most important determinant of BP, with both systolic and diastolic BP known to increase up to the age 60 years ${ }^{(1)}$. The BP pattern and the role of MTHFR genotype as a determinant of BP after age 60 years is less clear. The aims of this study, therefore, were to profile $\mathrm{BP}$ and to examine the role of MTHFR on BP in adults aged 60 to 102 years.

Data for this study were generated from an existing cohort, namely the Trinity, Ulster, Department of Agriculture (TUDA) Ageing cohort study $(n=5186)$. Detailed clinical, nutritional and lifestyle data were collected and BP was measured in accordance with National Institute for Health and Care Excellence (NICE) guidelines ${ }^{(3)}$.

BP was examined by deciles of age from 60 to 102 years and mean systolic BP (standard deviation) showed a plateau effect with age, ranging from $141.8(18.8)$ to $143.3(22.1) \mathrm{mmHg}$, whilst diastolic BP declined from $83.0(10.0)$ to $74.6(11.6) \mathrm{mmHg}$, in adults in the lowest decile (60-63 y) compared to the highest decile (86-102 y); data not shown. When the impact of MTHFR genotype on BP was examined, elevated BP in the TT genotype group (compared to CC or CT genotypes) was evident only in adults in age deciles 1 and 2 (i.e. adults aged 60 to $66 \mathrm{y}$ ), but not in age deciles 3 to 10 (i.e. adults aged 67 to $102 \mathrm{y}$ ). Data were combined for age deciles 1 and 2 and are shown in the table.

\begin{tabular}{|c|c|c|c|c|}
\hline & \multicolumn{4}{|c|}{ MTHFR $677 \mathrm{C} \rightarrow \mathrm{T}$ genotype } \\
\hline & $\mathrm{CC}(n=379)$ & CT $(n=378)$ & TT $(n=91)$ & $P^{*}$ \\
\hline Age (y) & $63 \cdot 2(63 \cdot 0,63 \cdot 3)$ & $63 \cdot 3(63 \cdot 1,63 \cdot 4)$ & $63 \cdot 3(62 \cdot 9,63 \cdot 6)$ & 0.710 \\
\hline Sex $n$ (\% males) & $141(37)$ & $151(40)$ & $24(26)$ & 0.056 \\
\hline On BP medication $n(\%)$ & $271(72)$ & $292(77)$ & $63(69)$ & $0 \cdot 114$ \\
\hline BMI $\left(\mathrm{kg} / \mathrm{m}^{2}\right)$ & $29.0(28 \cdot 4,29.5)$ & $29 \cdot 3(28 \cdot 7,29 \cdot 9)$ & $28.2(27 \cdot 1,29 \cdot 4)$ & 0.257 \\
\hline \multicolumn{5}{|l|}{ Systolic BP (mmHg) } \\
\hline All & $141 \cdot 2(139 \cdot 4,143 \cdot 1)^{\mathrm{a}}$ & $142.5(140 \cdot 7,144.4)^{\mathrm{ab}}$ & $146.4(142.4,150.4)^{\mathrm{b}}$ & 0.038 \\
\hline Males & $146 \cdot 2(143 \cdot 2,149 \cdot 2)$ & $147 \cdot 9(145 \cdot 0,150 \cdot 8)$ & $144 \cdot 3(136 \cdot 7,151 \cdot 9)$ & 0.578 \\
\hline Females & $138.2(135.9,140.6)^{\mathrm{a}}$ & $139 \cdot 3(136 \cdot 8,141 \cdot 7)^{\mathrm{a}}$ & $146.4(141 \cdot 8,151 \cdot 0)^{\mathrm{b}}$ & 0.006 \\
\hline \multicolumn{5}{|l|}{ Diastolic BP (mmHg) } \\
\hline All & $82 \cdot 0(81 \cdot 1,83 \cdot 0)$ & $81 \cdot 6(80 \cdot 6,82 \cdot 6)$ & $84 \cdot 0(82 \cdot 0,86 \cdot 1)$ & $0 \cdot 084$ \\
\hline Males & $84 \cdot 7(83 \cdot 0,86 \cdot 3)$ & $84 \cdot 3(82 \cdot 8,85 \cdot 9)$ & $84 \cdot 5(80 \cdot 4,88 \cdot 6)$ & 0.978 \\
\hline Females & $80 \cdot 5(79 \cdot 2,81 \cdot 7)^{\mathrm{a}}$ & $80 \cdot 0(78 \cdot 7,81 \cdot 3)^{\mathrm{a}}$ & $83 \cdot 3(80 \cdot 9,85 \cdot 7)^{\mathrm{b}}$ & 0.044 \\
\hline
\end{tabular}

Data expressed as adjusted means $(95 \% \mathrm{CI})$. Analysis by ANCOVA with adjustment for sex, BP medication, BMI and biomarker status of riboflavin. Values within a row with different superscript letters indicate significant differences by Bonferroni post hoc test.

These results show that systolic BP plateaus and diastolic BP declines from age 60 to 102 years. The elevated BP phenotype owing to MTHFR genotype is only evident from 60 to 66 years and is strongest in females. Given that the BP phenotype has been shown in RCTs to be responsive to intervention with riboflavin, further work should examine the interactive effect of riboflavin with $M T H F R$ genotype in older adults, targeting in particular females aged 60 to 66 years.

1. Joffres M, Falaschetti E, Gillespie C et al. (2013) BMJ Open 3, e003423.

2. McNulty H, Strain JJ, Hughes CF et al. (2017) Mol Aspects Med 53, 2-9.

3. NICE (2011) Hypertension in adults: diagnosis and management [CG127]. 